\title{
Jim Birley
}

\section{In conversation with Greg Wilkinson}

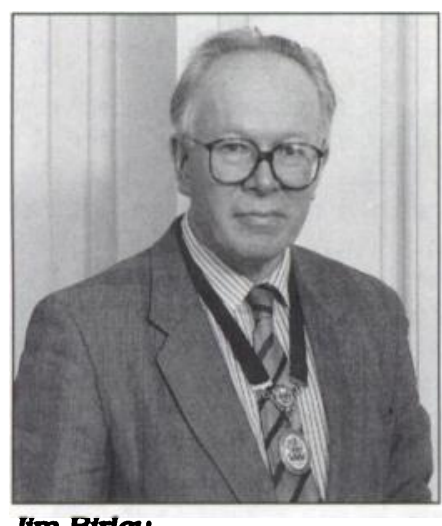

Jim Btrley
Dr Jim Birley, bom 1928, was educated at Winchester College, Oxford Universty, and St Thomas's Hospltal, London. He became interested in poychlatiy while working in the army, in Germany, as a (conscript) Junilor Medical Spectallst. After further medical experience and obtaining MRCP (London) he worked for a year with Dr Wiliam Sargant, and then went, in 1960, to the Maudsley Hospltal where he stayed for the rest of his career. He worked for three years in the MRC soclal Psychiatry Unit and was appointed consultant in 1968. He was elected Dean of the institute of Psychiatiry 1971-82; Dean of the College 1982-87; and President 1987-90. He rettred from clinical work on 1 January 1991. He was elected President of the Brttish Mecilcal Assoctation for 1993-94.
Your main interest has been seeing patients in thetr social context.

I have always had an interest in the social network in which people live, as well as in their own personal experiences. I suppose this arises from my own life, in so far as I grew up in a large family where there was a wide range of ages and types of people, in a village where everybody knew everybody else. If something was taken from a house you always knew where to look for it. At the time when I was beginning psychiatry there was a flourishing interest in social psychiatry. In fact, you could almost say it had its heyday from about the mid '50s to late '60s/"70s.

Who were the individuals that influenced you?

There were people at the Maudsley and the Social Psychiatry Research Unit itself. I was very influenced by the work which George Brown and John Wing had done in their famous 'three hospital' studies because I thought it was such a brilliant assessment both of the environment of the patients and of their mental states. The work was then extended to the family and George's work also showed that not being visited in a mental hospital (he looked at the visitors' record books) had an important influence on the discharge of the patients. In America there were other workers like John Clausen who did some beautiful descriptive studies of what it was like for a family when one of them was admitted to hospital. Goffman worked in Clausen's unit. Felix Post also wrote an excellent paper on the network of neurotic patients. I felt that this was an exciting area to work in.

At the Maudsley I learnt an enormous amount from Douglas Bennett about how to put social psychiatry into practice.

\section{How did your career develop?}

I got a consultant post shortly after completing my time at the Social Psychiatry Unit. One of my aims was to take part in what was then a novel concept for the Maudsley - looking after a catchment area and doing what Harry Truman might call buck stops here psychiatry' rather than passing people on to a mental hospital. This was a sort of social revolution within the hospital. In addition, it involved putting up social structures, to care for the long-term patients who would no longer be shipped off to Cane Hill. 
At the time, which were the other important centres in Britain that were tackling problems such as these?

I think a lot of the mental hospitals were developing various initiatives but they very much depended on the activities of individuals. Duncan McMillan was at Nottingham and Carse at Worthing with day hospitals. Freudenberg was developing many social changes within Netherne and insisting on meaningful activity for all patients. The benefits were recorded in the three hospitals study. Russell Barton was changing things at Severalls.

Did you have a clear idea of what you were trying to achieve?

I've never worked on a very long time-span but I certainly had a clear idea that within ten years the Maudsley should be providing a service for the population of what was then called Camberwell. Obviously it was easier for me to have some influence on adult psychiatry but quite clearly there were other aspects of psychiatry, particularly forensic psychiatry, which came into it as well. The last group to bring in to the Maudsley, which took a good deal longer, was the psychiatry of old age because they represented a particularly large burden for the service.

What did you do with these patients over this ten year span?

I think the first thing was that we were trying to stick with them. I became somewhat notorious for not discharging people, not from the wards but from some sort of outpatient or day-patient care, even if it only meant their coming up at very long intervals. Once people got out of touch they had to go through a whole series of hoops to get back into the system but if they were current patients that was not the case.

My other activity within the hospital was to work very closely with the newly appointed admissions officer at the Maudsley - a very able woman, Hazel McLean, whom I trained always to ask for a person's address. If this was in Camberwell, the service was told that the patient was coming in. This was a change from her providing a sort of restaurant service, asking the doctors whether or not they would like to admit the patient.
The other experience was developing services for people outside the hospital. I was involved in setting up a housing association which was interesting both in terms of how it was received by the locals, and finding local people with the expertise required to set it up. You needed architects, accountants, solicitors, housewives. All sorts of people were required.

\section{What was the time scale of this development?}

We started the housing association in the very early '70s and it's been running ever since. In those days things could happen quicker. We secured a house with a deposit from a local philanthropist and then we got a $100 \%$ mortgage from the borough. Converting the house and moving in took about nine months. That was our first house and all four houses were up and running within four to five years. We have recently bought two more flats. At the same time Douglas Bennett was setting up a factory which provided work for people and he got that going quite quickly. Although people talked about bureaucracy affecting the developments, I think it was easier to do those things then than it is now.

We always bought houses which had multiple occupancy and instead of a resident 'warden', we had a 'manageress', who lived locally. Therefore we were not changing the use of the house and didn't have to have a public enquiry and all the ensuing palaver. These houses gave people their own space and much more freedom. It was quite novel, in those days, to set up a house like this without any resident staff. But we were determined to do that and never regretted it.

You've mentioned housing, space, work: what else went into soctal treatment methods?

Not doing too much. We never had any group therapy, for instance, in our houses. People were left to their own devices as much as possible. But we wanted them to attend a day facility and most of them did. This was partly based on the view that people should get away from their families, even if they haven't got families, and should not stay in the same place all day. It was an attempt to give them a nonpatient role. They were treated as residents and not as patients, at least for part of the 24 hours if not for the whole day, and were expected to act responsibly in the house and indeed they did so, coping well with occasional crises which occurred there. That is one of the 
drawbacks of a mental hospital where, in a total institution, people's natural capacities atrophy, because they are never tested. This was what we wanted to avoid.

\section{Did the patients understand the treatment?}

I think they understood it very well. We actually did some market research with the original sample-people who had stayed in the Maudsley for more than a year. They all sald they wanted a place of their own and somewhere they could live with a certain degree of privacy. That was basically what we were trying to provide for them.

At this time you were elected to be Dean at the Institute of Psychiatry.

I became Dean of the Institute in 1971. I was willing to be elected although I knew nothing about the job because of natural curiosity as to what was involved. There were firmly felt feelings that the Dean should be, if possible, a clinical consultant. I think that this has continued to be a wise arrangement.

The Institute comes under threat with great regularity, for all sorts of reasons. A lot of people don't approve of postgraduate 'mono-speciality' institutes. But this seems to act as a challenge to ensure that it continues to attract first class research workers. The actual nature of the research is more difficult to determine. There were times when people wanted to push it in a particular direction or to do combined projects with the Postgraduate Federation. My feeling about research is that it is an art form. People find a particular style and particular theme which they like to pursue and they choose people with similar tastes, regardless of whether they work in London, Sao Paulo, or Brisbane. One other experience at the Institute was somewhat unusual. The addiction research unit took on some people who had been student activists from Essex University and in 1973-74 we endured a most bizarre mini revolution, reminiscent of the campus troubles at the Universities some years previously. That was a really stressful time, with the Institute being picketed and people saying they wanted to close it and really meaning it. It was certainly a searing and very fast learning experience for myself and for many other people.
But we've side-stepped your own research interest.

After becoming Dean my research interest ailed a bit until, almost by accident, I went to a talk by Professor Dick Rodnight on dimethyltryptamine (DMT) levels in the urine of psychiatric patients. DMT is a so-called 'natural' hallucinogen. I suggested that we investigate this on a larger scale. I am sorry to say that Dick told me later, when we were planning this work, that it was the first time that he had sat down with a Maudsley consultant and planned a proper systematic study together on any topic. I was very ably assisted by Robin Murray and later by Stuart Checkley. So my particular interest took a rather rapid switch towards biological psychiatry'. We recetved a Wellcome grant and a number of respectable papers resulted. But we had great trouble in measuring DMT in blood, which proved a major snag.

\section{I thought you were going to talk about life events.}

George Brown was very much the prime mover of these studies. It involved a rather unusual experience for most psychiatrists of interviewing a large number, say about 3400 ordinary people selected from various different places of work, about events in their lives. But most of that work had been completed by the late ' $60 \mathrm{~s}$. I think you should know that our first paper on this topic was turned down by the British Journal of Psychiatry as it was thought too far-fetched to suggest that schizophrenia could be precipitated by a life event.

\section{What's your thinking about the subject now?}

I'm pleased that this work, and the work on expressed emotion and the family, still resonates. It has got into the clinical system which I find gratifying. Julian Leff and others have taken the EE and family intervention work much further.

Would you say you thought that although every registrar knows about EE and how many hours of face-to-face contact patients and carers should or shouldn't have, for one reason or other it doesn't happen in practice to the extent you might wish in order to really effect some change.

That is probably true. I think one difficulty about it is that it would only work in a system where you know your patients fairly well. I've 
always seen it as being used in a more posittve way in terms of prevention rather than retrospectively. If you know that stressful events are looming, it is better to anticipate them rather than react later to the damage they may have caused. The life-events work has been tested widely and the results may be less clear than they were but the research on depression by George Brown and his team is extremely original and important. You are really making a general point that the percetved importance of social psychiatry has faded slightly. In terms of research it has been overtaken or got lost in the interest with biological psychiatry.

Why do you think that has happened; or is tt a political matter?

There are certain political advantages in biological psychiatry as it is much more attracttve for drug firms to fund it. In social psychiatry it is almost essential for a unit to have long-term funding. It cannot be done on a one year or even two year grant. At the time that George left the unit, John Wing became more involved with very important epidemiological matters: the Camberwell Register, the assessment of needs, and planning of services. The life events and family work dertved more from George's discipline of social anthropology.

How long is long-term in terms of social psychiatry or rehabilitation. Is it lfe-long?

My view of the trajectory, particularly of schizophrenia, which usually develops in the late teens, 20s and 30s, is to prevent as much early damage as possible, because most people tend to improve in the second half of their lives. If you look for change during the most stormy ages, you may not see very much. What you're trying to do is to allow people to live a life which doesn't atrophy their living skdlls, and maintain their dignity in the hope that when things get better they will be able to return to a normal existence.

One would like to think that providing the right sort of social network for people would reduce their need for drugs, for two reasons. One is that they may be in a less demanding environment, and the second is, you may be able to prevent relapses. The Northwick Park studies showed that if people have drugs intermittently the total dose they get during a period of time is actually higher because the treatment of relapses requires much higher doses.

Other aspects of social care that you haven't mentioned are your tnwolvement in the Southwark Assoctation for Mental Health and also the role of the general practitioner and the primary care teams.

In the Southwark Assoclation for Mental Health we developed a flourishing association which made an amazingly large amount of money from a second-hand shop, selling mainly good quality clothes in what most people would regard as a pretty unpromising part of East Dulwich. That money then went into various projects for people in Southwark. Funds were also raised at the Association's Annual Fête which we initiated, and held on the back lawn of the Maudsley (now, alas, built over). All the wards, and many local citizens combined to make it a hectic and very popular occasion, drawing a large crowd. Traditionally, the fortune-teller was supplied by 'The Villa' the Maudsley's most disturbed ward. The long line of clients waiting to hear their fate was largely composed of Maudsley staff.

I think it's fair to say that during the time I was at the Maudsley my contact with general practitioners, while good at a personal level, was poor in terms of long-term care and cooperation. We didn't make a great deal of use of general practitioners for the long-term care of the seriously mentally ill. I think there was a sort of collusion that the general practitioners were quite relieved they weren't asked to do it. The main problem was that they hadn't got a system of reacting to the non-event of people not turning up. They worked on a demand system and that's not an adequate system for long-term care. Things have certainly changed since then.

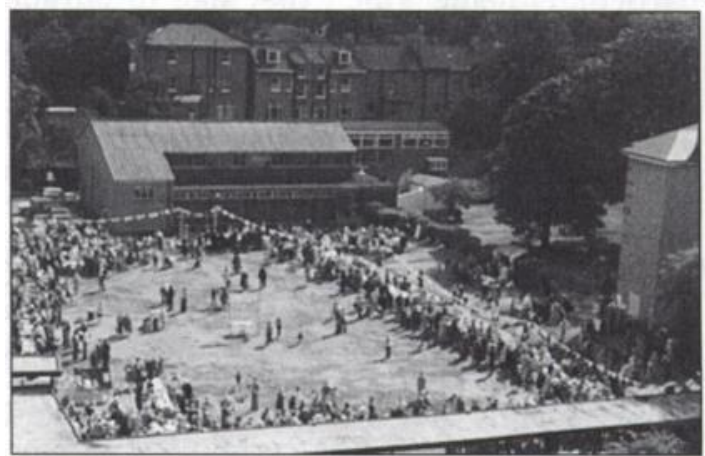

Annual fête, Southwark Assoclation for Mental Health 
You ran a walk-tn clinic.

I ran the walk-in clinic at the Maudsley, the Emergency Clinic. That was much loved by all the local services although visiting people felt that we were spoon-feeding the local GPs by taking their work off them. I don't agree. In London $30 \%$ of the population did not have general practitioners. We did varlous studies at the Clinic which indicated that the people who were referred by GPs were far less ill than the people who came spontaneously. It's still running so either the Maudsley needs it or the community needs It, Im not sure which.

\section{When did your role in the Royal College begin?}

I'd been Dean at the Institute for 12 years and Ken Rawnsley asked me, if I would be interested in applying. Before that time I hadn't really had much to do with the College. In fact, one of the things I was most closely involved in with the College was trying to stop it happening in the late '60s.

\section{What was your role in that?}

There was a group of us who felt that the proposed College was moving in the wrong direction in that the people involved wanted the glamour: maces, robes, a tough exam and the status, but they were not really interested in training. The emphasis should have been much more on training and less on glamour.

This may or may not have been a misconception but certainly we made ourselves extremely unpopular by threatening to petition the Prtvy Councll about this. The situation was really saved by a change of President. Francis Pilkington, from Moorhaven, was a much more understanding man, and he, Ken Rawnsley and Alec Monro listened to our points of view and to some extent, took them on board.

Out of this arose a major interest in training which the College has maintained; and also an organisation led by Anthony Clare called the Association of Psychiatrists in Training who were a vocal group but always, as it were, Her Majesty's opposition. It was never total confrontation. Finally they became incorporated in the Trainees Committee which has been so valuable in the College. So I think the whole episode, although it was somewhat heated at times, was quite a constructtve one.
And you were the Dean of the Royal College.

It was really dotting the l's and crossing the t's of what Ken Rawnsley and Thomas Bewley had been doing. We were rather more explicit about what was required in the training procedure and more explicit about the deficiencies. It was in my time that actual posts were named as being inefficient rather than just schemes. We also got senior registrars included in the inspection teams and I think that was very helpful. We tightened up the programme quite considerably and took some models also from the Joint Committee for Higher Psychiatric Training which was developing very strongly at the same time. I also had to fight on behalf of the College Inspection Teams which were quite expenstve affairs for local health authorities to fund. Some of them complained, but we managed to persuade them to go on doing it, and the Regional Postgraduate Deans were very helpful. We also launched a totally redesigned membership exam including a 'clinical skills' exam in Part 1.

Then you went on to the Presidency. What do you recollect about that perlod and your personal achievements?

The President has to represent the College, in circles within the profession and outside, when important issues or developments are discussed and planned. The main thing which hit us when I was President were the NHS 'Reforms' and this was a very alarming time. All of us, once we had read Working for Patients realised that it had been written by people who didn't understand the NHS. This came as a nasty shock. None of the health professions had been consulted and it was largely inspired by somebody who posittively disliked a large public spending 'socialised medicine' organisation. It had the fingerprints of Mrs Thatcher all over it. Struggling with a government who quite clearly hadn't thought it out and weren't prepared to listen was a very unnerving experience. It seems to me that people are still struggling with what is basically a bad design. There are so many contradictions, for instance, encouraging local care but at the same time encouraging competition. You can't have stx different hospitals all providing the same services. If you encourage competition for providing local care you can get bizarre situations, such as Bradford providing care for learning disabilities in Surrey. The present 
combination of PR rhetoric announcing wonderful achievements, and a lot of people being very demoralised, is very damaging.

The demoralisation that you refer to isn't articulated, to my mind, very clearly by the medical profession.

Certainly the BMA, when I was President last year, articulated it very strongly. Recruitment into general practice is dropping very seriously. People don't want to work in this new system. The difficulty is to articulate what people are demoralised about. There are different views about this. I'm sure it's not particularly to do with money. It's much more to do with working for a basically unsympathetic senior management, who got a very bad example to follow, from their political managers, by the way in which the Reforms were introduced. We were hit on the head with them. That's not a good way of getting the best out of people. It's bad management, not good management.

\section{How did you get involved with the Soviet Union?}

I had quite a lot to do with the Soviet Union because I was Dean when Ken Rawnsley was attacking the Soviet psychiatrists very strongly in Vienna about the abuse of psychiatry and they withdrew from the World Psychiatric Association (WPA). In 1989, I represented the College at the WPA meeting in Athens when the Soviets were readmitted under fairly strict conditions. I was in charge of the international team which went to Moscow in June 1991 to investigate what was going on and to interview some people whose diagnoses needed to be questioned. During that time I met the senior people there. The Soviet Union was run by a nomenklatura who had their separate system of hospitals and provided that was okay they weren't faintly interested in what was happening to ordinary people. There was a very extreme divide and mistrust between government and people and you sometimes get the feeling that the same thing is happening here.

You continued to have an interest in Eastern Europe.

We published the report of the WPA visit in August 1991 at a time when enormous changes were happening. We had met some remarkable people who had survived and wanted to revive psychiatry. I've been

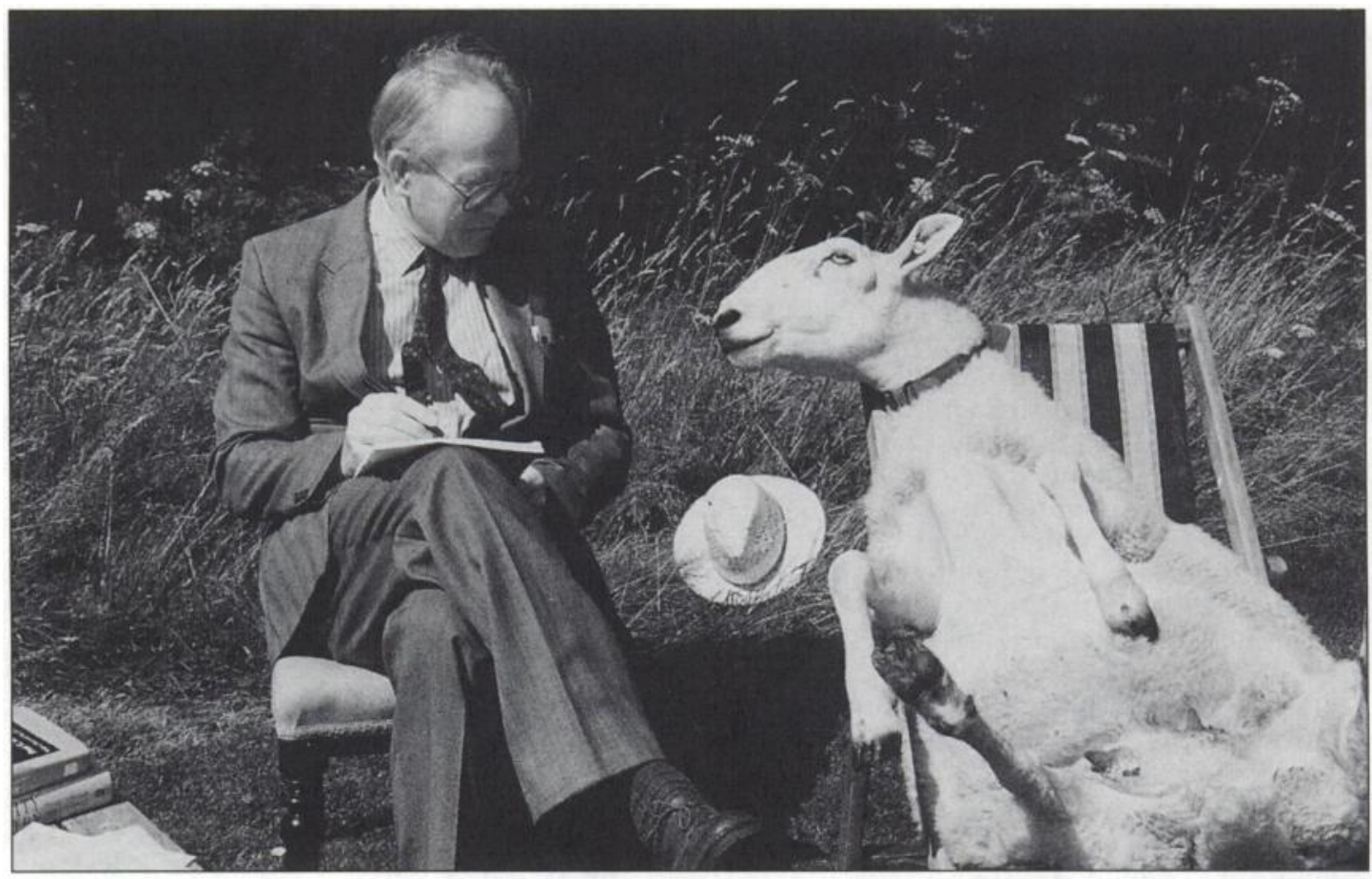

Dr Birley and friend 
involved, with many others, in trying to assist them. In Kiev, Dr Symeon Gluzman, a psychiatric-dissident who, after ten years in prison and exdle chose to remain in his country, has initiated the Ukrainian Independent Psychiatric Association which has already achieved some remarkable changes. I have also visited St Petersburg and Lthuania and, more recently Albania which is a very impoverished, but energetic place.

What's the story behind the picture of the sheep?

The farmer whose house we bought in Hereford lives just literally round the corner and we've become good frlends. He teased me that I was taking a lot of pictures of him working on his farm, and so he wanted to take a picture of me being a psychiatrist. It's a picture of me in psychiatric converse with a sheep.

Finally, what work remains to be done?

I am still Chairman of the Committee on Unethical Psychiatric Practices in Psychiatry (now the Ethics Working Group) which was set up mainly to look at what was happening in the outside world, and particularly the Soviet Union. We have switched our attention to the more painful problems of what is happening in this country. We are not the Ethics Committee of the College, but we are looking at potentially unethical situations. One particularly topical one is the ethics of reporting another doctor because of his or her incompetent performance. Everyone agrees that the profession needs to regulate itself more closely. The problem is how to make a system which is both efficient and fair. I am also Chairman of a project, funded by the Sir Jules Thorn Trust, to train community psychiatric nurses to have the skdlls which they need to work with patients and their families. They are taught family assessments and interventions, problem-orientated approaches and social, pharmacological and psychological treatments. The courses are at present running in London and Manchester, and are heavily oversubscribed, attracting excellent students. New training centres are in the pipe-line. The aim is to make the 'Thorn Nurse' as distinguished and competent as the 'Macmillan Nurse'. 